\title{
The Felonious Stereotyping of the Woman in Nollywood Films
}

\author{
Nonso Okafor \\ *http://dx.doi.org//I0.43 |4/ujah.v I7i3.13
}

\section{Abstract}

The woman, an embodiment of character and charisma, undaunted and passionate has been over the years viewed from varied perceptive, and this has permutated for characteristic ambiguity, hence the need for stereotyping. Stereotyping, is an erroneous assumptive conclusion, which inconclusively defines a character subject to probable outcomes and thereto premonitions. Film, an art of representing the reality in sequence which does not alter the reality in itself, has been a very good medium for communicating the happenings in the society and the major contenders (by this I mean the man, the woman, the children and their society). No doubt however, that this representation is a near truth, but has influenced the psychological dispositions (by way of standardization) and views of the people in the society. Therefore, this work examines the extent in which the film, IDEMILI (a film by Earnest Obi) has violated the character called woman, in its guise to representing the persona known as woman. Also, it explores the nature of the woman, by this I mean it reveals an in-depth understanding of the dynamics of the character of the woman, which has now formed the nature and nurture which the woman now embodies, thereby correcting the anomaly created in the process of revealing the nature of the woman, especially as being portrayed by Nollywood. This work also proffers dynamic representation of the female character which will reduce and consequently eradicate the stereotypic view of the woman in Nollywood films. 
Keywords: Stereotyping, Gender roles, Idemili, Woman, Violence, Nature, Nurture.

Preamble: An appraisal of the content and context of Nollywood films, shows that the films are created in a linear ideological perceptive; owing to its home-video aesthetic preferences. This preference, allows screen writers, the director, the director of photography to follow a conventional (or traditional) line of storytelling which reveals the lifestyles of the ordinary (emphasis mine) Nigerian, their joys, happiness, fears, pains and sadness etc and blows it out of proportion through glamour presentational style (emphasis mine). In this relationship between the actor and his art, the tendency to represent the characters as portrayed stereotypically is inevitable. This is a feature of cognitive psychology.

Nollywood films, an industry which has over the years attracted enormous attention both in terms of production and distribution, the second behind Bollywood in the world and the largest in Africa, these achievements deserves an ovation. Today, the industry has caught the attention and supports from the federal government that it has setup a special intervention fund for the industry and practitioners, an effort to boost and encourage more growth and creativity. These successes is evident in the fact that there is no Nigerian home where Nollywood films is not seen; either on the cable television networks or as a digital versatile disc/the digital video disc (DVD), video compact disc (VCD), with themes which cut-across the Nigerian society and its experiences.

For the purpose of this study, this work will focus on the power of the woman, her character and charisma; power in terms of will, dauntlessness, passion and love. 
A quick overview of the major character portrayal by the Nollywood actors is the characters or roles of the fathers, sons, husbands, kings for the male actors whereas the female roles includes mothers, sisters, daughters, prostitutes, wives, queens etc. This work in no way does not criticize the various roles depicted, as they are representational of the real world, serving its purposes. These purposes vary, owing to the various themes it projects. However, its reception has been welcomed by different quarters and groups in the society and this has informed the various audience perceptions which has over the years formed all the ideological constructs that dominates the society today, generating various ideological leanings and forming principles (nurture) ; hence, to Baron, Byron and Branscombe (2008) "your emotional state (happy, sad, fearful, etc) at any given moment influences what you perceive, your thought process, you motivation, the decisions you make, and interpersonal attraction".

The truth will remain that Nollywood films, character portrayal has over the years been over-exaggerated, and this has informed thought processes which has become the norms and believes of our society. Most men see women as inferiors, derogatable opposites, prostitutes, sex slaves, confusionists, unreliable and schemers. This same perception has cognitively ordered the personality and character of the person known as woman (emphasis mine). The degree of influence from the media and all its accolades cannot be over emphasised.

The Woman, through the eye of the camera has been projected in such a manner as criminal to their person and character, and everyone is watching and remoulding 
perceptions, believes, ideology, the woman not an exception especially the young generation.

Nollywood films have in many ways projects the personality of the woman, but for the purpose of this work, Idemili (20I4), a film by Earnest Obi and directed by Earnest Obi will be a source for digest.

Therefore, this work examines the extent in which the film, IDEMILI (a film by Earnest Obi) has violated the character called woman, in its guise to representing the persona known as woman. Though the film is a series of about six seasons, it will be examined to fully grasp the messages in the film. Also, it explores the nature of the woman, by this I mean it reveals an in-depth understanding of the dynamics of the character of the woman, which has now formed the nature and nurture which the woman now embodies, thereby seeking to correct the anomaly created in the process of revealing the nature of the woman, especially as being portrayed by Nollywood. This work also proffers dynamic representation of the female character which will reduce and consequently eradicate the stereotypic view of the woman in Nollywood films and by extension the society.

\section{Synopsis of Idemili}

A young maiden in her dreams sees herself constantly running without knowing what pursues her, and yet sees creatures that seem like humanoids.

It all began when Okwadike a hunter falls in love with Ekenma, who is the daughter of Agbonma, the descendant of Osimiri and priestess of Osimiri. According to tradition, the mother must pass-on the rite of priestess-hood to her virgin 
daughter to keep the lineage of worship, and hence, she is no man's wife.

Soon after, her mother the priestess passes on and tradition must now be fulfilled for her to continue the rite of priestesshood. The sudden demise of her mother was received with a shock and Okwadike now becomes her comfort in this time of loss. She was faced with troubling thoughts of how she must now fulfil the rites of tradition and stop loving him. He persuades her to let go of the priestess-hood and marry him, as he would protect her, but she was not convinced with the whole circumstances that has posed a big threat and challenge to her very existence.

Ekenma in her relentlessness, is persuasively being reminded of her duty by the priest her father, now goes ahead to be initiated into the cult of ogwugwu as the priestess the of Osimiri, while Okwadike prepares himself and charms for the spiritual warfare he is to embark on in order to win Ekenma' love and "prevent Ekenma from being subjected as a priestess for life without having to feel and express love and freedom of being" (emphasis mine) as a wife, with the goddess of Osimiri. For the purpose of the initiation, Ekenma is hypnotised and transmogrified into the spirit realm.

On her initiation day, Okwadike interrupts the ritual process and truncates the entire initiation, which now informs the entire Idemili story. Okwadike and his warriors die in this singular action that day, as they were all turned into sanddusts. Upon realisation of her action, Ekenma regrets killing Okwadike and since she could not bring him back to life, she runs out from her father's presence and from the village far away that no one could find her. 
Ekenma, now tries to get married after many years, but is now haunted by her obligation to the goddess of osimiri, in dreams, in her relationship; and she most of all does not have a clue of her origin and background.

Her life obligations get others entangled in her web of troubles, which is unknown to her real world, and they were all caught in it and cannot escape from it. Prince Afamefula was made impotent, and his family had to find a solution to appease the goddess of osimiri, the Queen, his mother falls out with the King, the Princess of Ahamba caught also in the web for marrying the prince when the prince is yet to fulfil sincerely the traditional rites of appeasing the goddess of osimiri.

Ekenma, with the help of Kamsiyochukwu now sought to unravel her mysterious origin and obligation which was initiated by her mother and the secrets by her mother; her success will determine the success and freedom her entangled victims may enjoy in the long run.

\section{Characterisation in Idemili}

The film Idemili, is a film which centres on the roles of women in the growth of their family, which extends to other people and by extension, the larger society. The screenplay revolves around four main characters, that is the story is embodied in the character of this four; Ekenma, Agbonma, Queen Mother, and ljele; and this is due to how each of their actions help to bring the story to its climax, as every other character' role is somewhat supportive to the actions of the main four. They determine the outcome of the film and the significance of the other characters in the film. 
Ekenma, the protagonist in the film Idemili is presented as one who really knows nothing about her origins, has no say about her future (predestination), lacks will of purpose, manipulated to kill, runs from her challenges, constantly pursued by unknown spirit but cannot confront them in her dreams and surrounded by people she thinks are close relatives of hers. She embodies a character that lacks the power to make decisions of her own; that she constantly expresses her inability to understand what is happening to her. In seasons 2 and 3 of Idemili, Ekenma, expresses total state of confusion and completely dependent on Kamsi for courage and motivation.

In another vein, she is presented as an object of ridicule to the community during her marriage solemnisation to Afam. In her words

"I left the town covered in shame" (season 2)

She is portrayed here, as an object of ridicule to the entire community after failing to fulfil the marital solemnization with the prince Afam. In other situations where she was unable to express her self-will and make sound judgments in the film, especially her scene with Kamsi in the hotel room, is a complete belittling of her personality as a being. Her reaction in this scene, as portrayed by the writer and director, is extreme and inexcusable. Extreme because, her nature has been belittled, that man now is the rationale for her to understand her mother's reasons for her actions. She naturally has the innate ability to decipher the good and bad in her decision making processes. Inexcusable because, it's a stereotype of role play and to the discourse is felonious.

In all her appearances in the film, she is portrayed as a character without self-will, unable to make sound judgment, 
as her few decisions where counterproductive in all ramification, which inadvertently sets her as a weak gender.

The Queen mother is another character that is expressively possessive, full of greed, jealous, wicked, power hungry, and a witch, insubordinate, ambitious and full of pride.

In other to prove her worth and significance in the life of her son, she exerts time without number the reasons behind all her decisions and actions for her only son, the heir to the throne:

Son: Mum, I am very confused

I don't know what to do

Queen: Don't be, that is why you have a mother

(Season 2) emphasis mine

In another development, where the king insists the prince take certain decisions, the Queen advises:

Queen: Leave you father to me, have faith in your mother

(Season 2) emphasis mine

The emphasis suggested here is quintessential to the role of a mother in the life of her offspring. I believe no mother hates her children, "their actions are good to them". But, on the long run her actions in this film where all leads to the total collapse of tradition, death of the innocent and wicked to the entire community and by extension the neighbouring community.

Agbonma in this film is portrayed as the mother of Ekenma, although the film (screenplay) is unsure of her person from the beginning in season one to the final season left her character obscure. 
She, as all mothers would want the best for their daughter and by extension, other children. She is loving and caring and supports her daughter's yearnings and demands. Ekenma loves her so much, that her sudden demise had a traumatic effect on her. She wished that Ekenma, her only daughter continue in service of worship as the priestess of Idemili, as this gave her the fulfilment she would ever had wanted or wished for.

She is seen as a wicked woman, who fed her daughter will all lies and distanced her from her father, relatives and made her life a lie. Ekenma expresses her displeasure with the manner her left her confused and alone after her demise:

Ekenma: ... all the money put together cannot make up the fact that my mother lied to me... she told me that my father died, that was what she said.

(Season 2)

Although, in her few appearances and testimonies from other relating characters, she was very kind, loving, caring, fun loving, and very rich (which is a character ambiguity flaw on the side of the screen writer and director) (Emphasis mine).

Her reasons for leaving her daughter out of her family matters is unknown, but from the sequence of actions, she had the best intentions for her daughter, to be free from all burdens and live a fulfilled life after her, yet this is contradictory of the story in season one.

ljele (priestess of the gods), progeny of her ancestors, who now bears the burden of her father's mistakes and always reminded of this by the Queen mother, to taunt her 
priestess-hood and prevent her from carrying out her religious functions.

She like most mothers keeps the secret of her father's mistakes from her son, who now is worried by the circumstances that prevent his mother from performing religious functions to the utmost. In his quest to find lasting solutions to prevent evil in the society, he asks his mother:

Son: There is always something to do to stop evil from thriving; you thought me that mother.

ljele: I thought you a lot of things; but this is one of those things you should not learn.

Son: And yet you teach it?

ljele: Learn that which you must, the rest you leave for the gods.

(emphasis mine).

Does this singular act make her a bad woman or connote meanness?

She is now compelled by circumstances to reveal the past to him but was so mild with the consequences of her actions and outcomes, thereby creating future problems for the community and son who someday will continue the line of priesthood.

The truth about these characters in Idemili is that they all had the best of motives for their children to help them succeed in life and become well than they are, and that is a true characteristic of a mother. But, from its portrayal in Idemili, consequent to action-reactions construct in communication, is felonious (that is the negative perspective in this context). 


\section{Gender Stereotyping and its Effects.}

Ms Maureen Bohan, a consultant expert in her study defines gender stereotyping as preconceived ideas whereby (males) and females are arbitrarily assigned characteristics and roles determined and limited by their sex. Sex stereotyping can limit the development of the natural talents and abilities of (boys) and girls, women and (men), as well as their educational experiences and life opportunities. (20II) (emphasis mine)

In addition, Brannon put gender stereotype as ...consisting of beliefs about the psychological traits and characteristics of, as well as the activities appropriate to, men or women. Gender roles are defined by behaviours, but gender stereotypes are beliefs and attitudes about masculinity and femininity.

It goes ahead to state that:

The concepts of gender role and gender stereotype tend to be related. When people associate a pattern of behaviour with either women or men, they may overlook individual variations and exceptions and come to believe that the behaviour is inevitably associated with one gender but not the other. Therefore, gender roles furnish the material for gender stereotypes. (2004:160)

Stereotyping, is not a new subject in the mainstream of intellectual discuss. An inquiry into the origin of the theory dates as far back as the origin of mankind where men designates specific responsibilities to the woman and they graciously accepts the responsibility (roles) and this has over the years been practiced without any form arbitrariness or insubordination. However, due to the advancement of knowledge, role play can be conceptualised to meaning roles which are complimentary to that of both sexes. Hence, the 
short falls in this new age advancement, has led to the various revolutionary campaigns making the rounds in the world today. This study is therefore concerned with its negative connotations especially as it relates to the female gender as portrayed in Nollywood films, although not all theorists agree to this, but research has shown that the vast majority who experience this form of stereotyping are exposed to the theory known as Stereotype threat : a phenomenon that occurs in situations in which the presence of negative stereotypes affect the performance of those to whom the stereotype applies (2004:184); otherwise there would not have been a rise in social divide in the society today like Feminism,Womanism, or even Masculinity and still count.

In Nollywood films, gender roles are what play out in the films, where men take on roles associated with men, while women take on roles associated with their gender and hence, blown out of proportion (larger than life acting). These construct is what this paper centres on, in order to bring to bear gender stereotypes especially as it relates to Nollywood film productions where the roles played by the woman are roles which portray them as a lesser gender or threatening to their very existence, character-wise.

Agatha in her article puts it thus:

The representations of women in Nollywood videos fail to depict them in ways which evaluate the sordid reality of things in the real world. To achieve this false representation, the filmmakers have resorted to reversal in roles of women and men in the society.

She went further to describe the role portrayal as the "male gaze" perspective 
As men have traditionally been in power in the film industry, Theorists believe that the camera shows us the world through the stereotype eyes of the "male gaze"

(2010)

The 'male gaze' is now a term used for describing Nollywood film-makers owing to the fact that they have over the years gratified the female gender and engendered their personalities. The consequent audience perception could be more devastating especially as it concerns the youth in the society. Gender stereotype can be very influential and they affect the conceptualisation of the woman thereby establishing them in social divide which may now represent what people think about the woman, what believe they have of the woman, and this goes a long way to establishing judgments about the woman and their lives.

Today in Nollywood films, most female roles includes mothers, mother in-laws, house-girls, students, wives; and on a scale of justice as wives and mother, they either embody the traits of wickedness as wicked mothers who do not want the father, a particular son or daughter, or a neighbour to succeed; or they are wicked mother in-laws or witches holding the destiny of their daughter in-laws or son in-laws. On the other hand, they are student prostitutes otherwise known as runs-girls; or housemaids' seducing their masters or their masters' son, getting pregnant and eventually taking over the home and hence, tagged gold-diggers eventually.

The worst case scenarios are the unmarried ladies who are seen as sex toys; object for battering, objects of nude or near nudity as gratification for the men, ostentatious, frivolous and materialistic. 
Mabel discusses this when she quotes a theatre artist in her work:

I am a theatre artist and I do not like most of the images that assault us women in these films. Nigerian women are often portrayed to be after men, money and mindboggling gratifications. Where do our film makers find these women? Why do our women agree to act these demeaning roles and wear what they wear? (2008: I I2) An online brain parody of the man and the woman shows this image:

\section{THE FEMALE BRAIN}

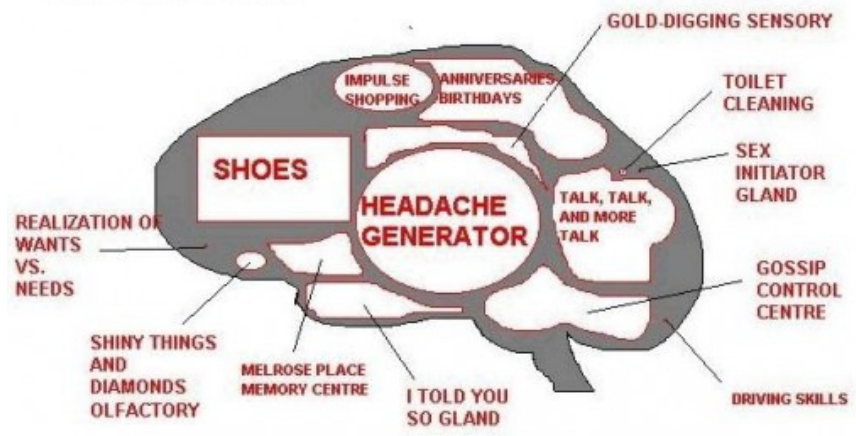

FOOTHOTE: The "Put Oil into the Car" and "Be Quite During the Game" glands are active only when the "SHIWY THILGS AND DaAmonos" OLFactory has been satisfied or when there is a shoe sale.

\section{THE MALE BRAII}

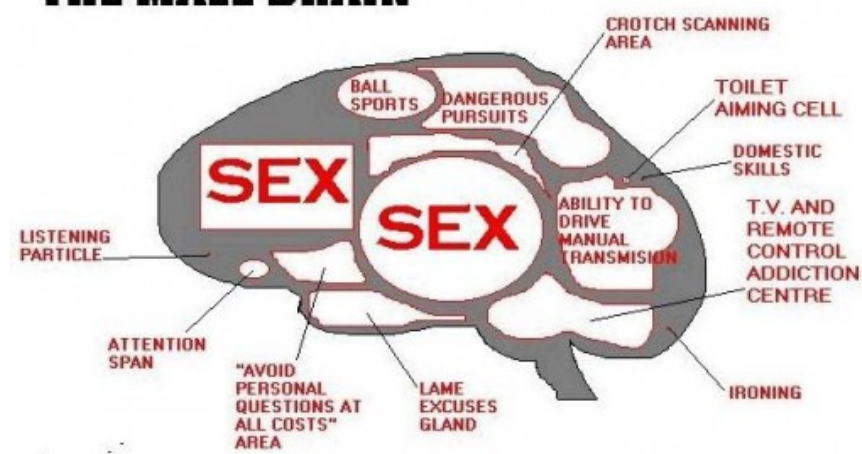

FOOTNOTE: the "Listening to children cry in the middle of the night" gland is not shown due to it's small and underdeveloped nature. Best viewed under a microscope. 
Source:http://mythicalstorm273.hubpages.com/hub/MensBoxes-and-Womens-Crossing-Lines-The-Way-We-Think.

This is sarcastic but truthful owing to implicit implications of the objects seen. Subject to the man's brain parody which is occupied by sexual activities and gratifications, many thanks to the visual contents in and around his environment, which has now given rise to this parody. Society norms granting male control or dominance over the female; acceptance of violence as a way to resolve conflict; notion of masculinity linked to dominance, honour and aggression; rigid gender roles are all various leads to gender violence. These objects are images presented to the mind during various process or factors like in watching films, observing your environment, reading and or listening something; all these cause some levels of violence.

Violence is a means of control and oppression that can include emotional, social or economic force, coercion or pressure, as well as physical harm. It can be overt, in the form of a physical assault or threatening someone with a weapon; it can also be covert, in the form of intimidation, threats, persecution, deception or other forms of psychological or social pressure. The person targeted by this kind of violence is compelled to behave as expected or to act against her will out of fear (UNHCR: 2003).

Violence cannot be attributed to a single factor. Its causes are complex and occur at different levels (the LANCET: 2002). It went further to state that

...To represent this complexity, the report uses an ecological model with four levels. 
This work is more concerned with the fourth levels; which states:

the fourth level looks at the broad societal factors that help to create a climate in which violence is encouraged or inhibited: the responsiveness of the criminal justice system, social and cultural norms regarding gender roles or parent-child relationships, income inequality, the strength of the social welfare system, the social acceptability of violence, the availability of firearms, the exposure to violence in mass media, and political instability.

(The LANCET: 2002)

The United Nation High Commissioner for Refugees (UNHCR) article adds:

society includes the cultural and social norms about gender roles, attitudes towards children, women and (men), the legal and political frameworks that govern behaviour, and the attitude towards using violence as means of resolving conflicts (UNHCR:2003)

The effects to these according to Adesina Lukuman in his work which discusses Audience perception of portrayal of women in Nigerian home video films:

"For me, the influence of the portrayals on me (Oluwatosin) is that they make me angry and give me reason to fight against the domination of women. I rarely identify with any of the women they show in the films especially the ones that are shown in a negative way. Instead of identifying with them, they make me angry and I wish to fight with those who produce these negative portrayals of women and wish to change the culture on which I think such negative portrayals are based (Oluwatomi, from the second group)". 
Accordingly, Adesina Lukuman further pointed out Chizima's opinion, which was the most agitative among the female participants in group two; she demonstrated her provocative perception and interpretation of Nigerian films as this:

"It is just unfortunate that African women are too fearful; they do not have high self-esteem. And that is why the films can get away with all their denigration of women. For me, I reject them, but even though I can reject them, they still have an effect on the image of women generally, and that is why we must not only see them as rubbish or just entertainment, as most of us want to see them. We must reject them entirely and let the men who are producing them for their own purposes know that we do not like the way they portray us. We should let them know that we have our own selfesteem. It is only a woman that has low self-esteem that will look to a man for her confidence. I do not need a man to hold my hand to cross the street; I do not need a man to feel good. I do not need him to be confident. I might need him as a husband and it ends there". (2010:203)

The question now is how many of Oluwatosin and Chuzima are out there, angry, agitative and reactive about the manner they are portrayed in Nollywood films; how long should this quest continue and what perception does this uphold for the millions of young girls in the future who somewhat might be exposed to future dangers of violence perpetuated by men? And this time may become overwhelmingly difficult to contain. The time to act is now.

\section{Recommendations}

The recommendations here are not critical analysis of the script (content and context), but an appraisal of the film 
subject to its major ideological construct, that is priestesshood, which is a gender discuss.

Idemili, a well written piece, has several inexcusable mistakes which would have been averted during the making of the film. Individuals have distinct muse when it comes to film appraisal, but of most noticeable is the screenplay or story, acting (role-play and execution), costumes and make-up, music and soundtrack, effects and all. But for the purpose of this paper, the storyline (screenplay) and acting will be appraised.

First, the storyline which must be made emphatically clear that it is a great idea, but its execution is very poor. It is discovered that the story's continuity is such that lacks a linear sequence of actions. Take for instance, Egbe-igwe to Okwadike which should be the major theme and lead of the film Idemili:

Egbe-igwe: '...she is wife to no man'

(Season I)

In Season two Kamsi presented a box to Ekenma, a gift from her mother which can only be given her before marriage:

Kamsi: 'she said I was meant to give it to you before you get married'

Also, we see Ekenma narrate the content of the letter from her late mother to Kamsi's mother (Aunty Deborah) and Kamsi;

Ekenma: '...she reminded me that I could not take the beads off my waist until I find the right man, only then could I take them off

(Season 2) 
These actions are contradictory and as such are a flaw of the script and directorially. The director did not take into consideration the unfolding of actions in the series. Although, the bead eventually falls off her waist during her trip to Enugu with Kamsi, which ridicules the entire process of waiting for the priestess by the worshippers of ogwugwu for the many years they did and should have been cut-off from the entire story. This is simply an unnecessary suspense and intrigue that has marred the relativeness in the film.

Acting, in this film is still unprofessional and most of the characters were falling in and out of character, perhaps it can be attributed to the disjointed nature of script which lack incongruity.

Therefore, it is significant to state here that screenplays are the first step to any successful film, whether be it a 'cliché', or fiction or non-fiction. The story must have a logical beginning, logical middle, and a logical conclusion. Most Nollywood films fall short of this prerequisite and this has bedevilled its eventual unprecedented success. The ideas are unparalleled, but the scripting and execution has always been the bane of these films. Patience must be a virtue to inculcate in film making and then professionalism.

Idemili story can be reproduced to reveal the Nigerian culture and how her people surmount the many hurdles posed by their cultures. Idemili, can be a story which reveals the crucibles of a median that is predestined to become a priestess, but could not serve wholeheartedly due to her affections (or love) for a man, and then eventually overcomes at the end. This can become a subject of discourse in Predestination and man. Intrigues, suspense, good shots (POV), sound and light effects, equitable costumes and make-up can 
be fully utilised to reveal how the success was achieved. The audience is easily spellbound with good concepts.

Mismanagement of concepts and ideas must be avoided to produce a great movie or film. There should be not confusion of visions and missions in the making of films. Themes should be simple, which reflects the significance of the literary icon as the eye and mirror of the society.

Issues on gender roles must be treated with utmost caution, as this eventually informs the ideology and philosophy of a society in the long run, which might become a positive or negative trend in the society thereby building quarters for disunity, acrimony, stereotypes, and by extension violence. Rather, a more gender sensitive issues can be projected for purposes of national and world peace, love and unity.

Respect should be accorded the woman, and not subject her to public disdain in the guise of entertainment or masculine gratification.

\section{Conclusion}

The nature of humans (specifically the Woman) as discussed in this paper is due to the nurturing received through life experiences. The truth in reaping that which is sowed cannot be taken apart from this subject matter. Art, by this I mean literary works which by extension are the products of narration in most theatres and film industries, mirror the society and serves as the conscience of the society. Nollywood, is not exempted in this form of responsibility to her society, hence its products has an influence on her esteemed audience. The reactions from the scholarly works gathered and the continued subjugation in the form of stereotype, has a grieve influence on the future generation, 
which can take a leap from the contents received from Nollywood films as the norm of the society. This is an unhealthy practice, which can be discontinued to save the society from an anticipated social divide, which might not be ever remedied.

Hence, it is germane to state that, Nollywood in its effort to mirroring the society has feloniously stereotyped gender roles, which over the years has risen concerns especially from the negatively affected, the Women, who are the majority no doubt.

It is of quintessence to posit that the art of stereotyping has a more negative influence than positive. This is subject to its ideological constructs; hence it now forms the philosophy of the society that allows such practice, thereby subjecting the group to ridicule and shame.

For a continued social harmony and the preservation of our natural nurturing, these words by Stephen Sondheim in his musical lyrics, should serve as reminder to every activity we embark upon, knowing full well that one day we will be no more to return the hand of the clock.

How do you say to your child in the night?

Nothing's all black, but then nothing's all white

How do you say it will all be all right

When you know that it might not be true?

What do you do?

Careful the things you say

Children will listen

Careful the things you do

Children will see and learn

Children may not obey, but children will listen 
Children will look to you for which way to turn

To learn what to be Careful before you say "Listen to me"

Children will listen

Careful the wish you make Wishes are children

Careful the path they take Wishes come true, not free

Careful the spell you cast

Not just on children

Sometimes the spell may last

Past what you can see

And turn against you

Careful the tale you tell

That is the spell

Children will listen

How can you say to a child who's in flight

"Don't slip away and I won't hold so tight"

What can you say that no matter how slight won't be misunderstood

What do you leave to your child when you're dead?

Only whatever you put in its head

Things that your mother and father had said

Which were left to them too

Careful what you say

Children will listen

Careful you do it too

Children will see

And learn, oh guide them that step away

Children will glisten

Tample with what is true

And children will turn

If just to be free 


\section{Careful before you say \\ "Listen to me"}

(2014)

Source:http://www.allthelyrics.com/lyrics/sondheim_stephen/c hildren_will_listen-lyrics-I242795.htm|\#ixzz3Y7Ua3AWE

Nonso Okafor

Centre for Promotion of Ethics, Values and National Integration Abuja, Nigeria

\section{Works Cited}

Adesina Lukuman Azeez Audience Perception of Portrayals of Women in Nigerian Home Video Films. Journal of Media and Communication Studies. Vol.2 (9) PP 200-207, November 2010

Agatha Ukata Conflicting Framings of Woman in Nollywood Videos.African Nebula I (I), February 2010

Brannon, L Gender Stereotypes: Masculinity and Feminity in Gender: Psychological Perspectives. 4th Edition PP 159-186. Pearson 2004

Ernest Obi Idemili 20I4

Etienne G Krug, James A. Mercy, Linda L. Dahlberg, Anthony B. Zwi The World Report On Violence And Health. THE LANCET Vol. 360. October 5, 2002.

Mabel E. Evwierhoma Women Through the Eye of The Camera: The Aesthetic Challenges of Nigerian Films; In African Through the Eye of the Video Camera, Edited by Foluke Ogunleye. Pp 112, Academic Publishers, Swaziland 2008 
Ms Maureen Bohan Steering Committee for Equality Between Women and Men (CDEG); Study On Combating Gender Stereotypes In Education, 20I I

Robert A. Baron, Donn Byrne, Nyla R. Branscombe Social Psychology: Eleventh Edition, Prentice-Hall of India Private Limited, New Delhi 2008

Sondheim Stephen Into the Woods (film): Children Will Listen. Walt Disney Pictures 2014

United Nations High Commissioner for Refugees Sexual and Gender-Based Violence against Refugees, Returnees and Internally Displaced Persons: Guideline for Prevention and Response. May 2003

http://mythicalstorm273. hubpages.com/hub/Mens-Boxes-andWomens-Crossing-Lines-The-Way-We-Think. 